\title{
Phytoconstituents evaluation and antimicrobial efficacy of the crude flavonoids and saponins rootbark extracts of Terminalia avicennioides and Ficus polita
}

\author{
Hamidu Usman $^{1 *}$, Abubakar U Kaigama ${ }^{1}$, Olajide O Ibisagba ${ }^{1}$, Ali M Fulata ${ }^{2}$, Ibrahim A. Ahmed ${ }^{1}$ \\ ${ }^{1}$ Department of Chemistry, University of Maiduguri, P.M.B 1069 Maiduguri, Nigeria \\ ${ }^{2}$ Department of Remedial Studies, Ramat Polytechnic Maiduguri, P.M.B 1070 Maiduguri, Nigeria
}

\section{A R T I C L E I N F O}

Article Type:

Original Article

\section{Article History:}

Received: 20 October 2017

Accepted: 10 January 2018

\section{Keywords:}

Antimicrobial activity

Medicinal plants

Ficus polita

Terminalia avicennioides

Phytoconstituents

\begin{abstract}
A B S T R A C T
Introduction: Plant is a friend to man in survival as it gives him food, shelter and medicine beyond the ages of human civilization. This paper evaluates the phytochemical constituents and the antimicrobial activities undertaken on Terminalia avicennioides and Ficus polita.

Methods: Phytochemical screening was conducted on the root extracts according to the standard procedures. The hole-in-plate disc diffusion technique was used to determine the antimicrobial activities of the crude saponins and crude flavonoids against the tested microorganisms used in this study.

Results: The results revealed the presence of alkaloids flavonoids, saponins, sterols, phlobatannins and terpenoids. The antimicrobial activities presented as diameter of inhibition zones showed high activity value of $34.70 \pm 0.57 \mathrm{~mm}$ against Staphylococcus aureus and Pseudomonas aeruginosa at a concentration of $100 \mathrm{mg} / \mathrm{mL}$ and by crude flavonoids portion of T. avicennioides while the least activity was shown by crude saponins portion of $F$. polita at a concentration of $25 \mathrm{mg} / \mathrm{mL}$ with value of $9.67 \pm 0.58 \mathrm{~mm}$ against Shigella dysenteriae. The crude flavonoids inhibited the growth of Candida albicans at all concentrations while resisitances were found towards the crude saponins portion of both plants. Hence, flavonoids extractives from the two plants appeared to be more effective than the saponins against the tested microorganisms. Conclusion: These findings justify their potential use as drug-plant against bacterial-related infections in African traditional medical system and also suggest a possible insight for the isolation of bioactive chemotherapeutic agents from T. avicennioides.
\end{abstract}

Implication for health policy/practice/research/medical education:

The phytochemical evaluation of the rootbark extracts of T. avicennioides and F. polita revealed the presence of alkaloids flavonoids, saponins, sterols, phlobatannins and triterpenes. Anthraquinones was absent in both extracts. The extractives exhibited tremendous activities on the test microbes; however, crude saponins portion was inactive against C. albicans. These results are not unrelated to the phytochemicals present in the extracts. The results are indicative of the possible use of these plants for preparation of new drugs.

Please cite this paper as: Usman H, Kaigama AU, Ibisagba OO, Fulata AM, Ahmed IA. Phytoconstituents evaluation and antimicrobial efficacy of the crude flavonoids and saponins rootbark extracts of Terminalia avicennioides and Ficus polita. J Herbmed Pharmacol. 2018;7(2):106-111. doi: 10.15171/jhp.2018.18.

\section{Introduction}

Ethnomedicine is a multi-disciplinary complex system which involves the use of plants, spirituality and the natural environment and has been the source of healing people for millennia (1). The use of plants for medicinal purposes dates back to the Vedic period (10th-12th BC). However, up to a few decades ago herbal medicines were replaced by synthetic medicines due to their fast-relative effects. More so, side effects posed by allopathic medicines are reverting the global trend towards green medicine. 
According to the World Health Organization (WHO), an investigation into the safety, properties and effectiveness of medicinal plants should be continued, bearing in mind that they stand the chance of unfolding variety of potent drugs especially antimicrobial compounds. Being the largest producer of herbal medicines, India is considered the world botanical garden (2).

The threat of rapid development of drug-resistance by pathogenic organisms has led to the emergence of new concepts in drug therapy which is the 'combination therapy'. This therapeutic approach to treatment specifically favours the use of crude natural products which are thought to have many active ingredients working in synergy to exert the observed pharmacological effect (3). However, the variation of the constituents in herbal preparations could be due factors like to genetic, cultural, and environmental; have made the use of these medicines more challenging than it would have been (4). The global campaigns for the search of new bioactive agents with fewer side effects and greater activities have led to the screening for bioactive compounds in many medicinal plants of the Tropics (5) especially Terminalia species (Combretaceae) and Ficus polita. The selection of these species was based on its application in traditional medicine in Africa and other parts of the world for the treatment of microbial infections. Therefore, studies into medicinal plants with antimicrobial properties are expected to enhance and validate the use of such plants against bacteria related infections. The active principles of many drugs found in plants are due to secondary metabolites (6). Hence, basic phytochemical investigation of the extracts for their main phytocompounds is very important. T. avicennioides Guill. \& Perr. family: Combretaceae, are locally called in various Nigerian languages as Kpace in Nupe, Kpayi in Gwari, Baushe in Hausa, Igiodan in Yoruba, and Edo in Igbo; have been reported to possess antimicrobial activities (7-11).

Ficus polita Vahl. is a tropical evergreen shrub or small tree of the family Moraceae, usually grow up to $15 \mathrm{~m}$ and reaching up to $40 \mathrm{~m}$ tall. The leaves are occasionally harvested from the wild for food. Like most other Ficus species, the fruits are sometimes eaten as aphrodisiac and stimulant. Ficus polita is known as Hartblaarvy, Heartleaved fig, polish fig, rubber plant, wild rubber fig, or wild rubber tree. It is locally called "durumi" in Hausa. The fruit and young leaf are chewed for dyspepsia (12), infusions from the bark and roots are utilized in the management of infectious diseases, abdominal pain, dyspepsia and diarrhoea like many of the species from this family (12-14).

In our continuous search for medicinal plants with antiinfective potency from this part of the Tropics especially those with antimicrobial effects, the authors carried out a survey on these plants with the view of finding the most active for further studies. In this regard, this study was designed to evaluate the phytochemical constituents and the antimicrobial activities undertaken on T. avicennioides and F. polita.

\section{Materials and Methods}

Plant collection

Fresh root barks of T. avicennioides Guill. \& Perr. and F. polita Vahl. were collected respectively from AyetoroGbedde, Ijumu Local Government Area, Kogi State and Goniri Village, Bama Local Government Area, Borno State, Nigeria. The samples were identified by a Taxonomist, and the plant samples were deposited in herbarium of Research Laboratory in the Department of Chemistry, University of Maiduguri, Nigeria.

Sample preparation and extraction

The root barks samples were dried under shade with intermittent weighing until a constant weight was obtained. The samples were pulverized using wooden mortar and pestle. The powdered materials (400 g) were extracted with the mixture of two solvents, $80 \%$ ethanol and $20 \%$ distilled water using reflux apparatus. The extracts were filtered and concentrated under reduced pressure and temperature.

Separation of crude saponins and flavonoids

The method of Won et al (15) was adopted. Twenty grams of the crude extracts of each sample were dissolved in n-hexane, the insoluble residue was then suspended in distilled water and diethyl ether added to it. The distilled water fraction was then partitioned with n-butanol. The water portion was then discarded. The n-butanol fraction was then treated with $1 \% \mathrm{KOH}$ and separated to afford the first n-butanol fraction (saponins). To the residual $1 \% \mathrm{KOH}$ portion was added conc. $\mathrm{HCl}$ and then further partitioned with n-butanol until exhaustion to obtain the second n-butanol fraction (flavonoids) as schematically presented in Figure 1.

\section{Phytochemical evaluation}

Phytochemical evaluations of the root bark extracts of T. avicennioides and F. polita was independently carried using conventional phytochemical methods as described earlier by several authors. The tests for steroidal nucleus (Salkowski's test) and terpenoids were described by (16), free and combined anthraquinones, tannins and phlobatannins tests were as described by (17), test for saponins by (18), alkaloids by (19) and flavonoids by $(17,19,20)$.

Antimicrobial evaluation

Test microorganisms

Five pathogenic microorganisms namely: Salmonella typhi, Shigella dysenteriae, Pseudomonas aeruginosa, Staphylococcus and Candida albicans were clinical 


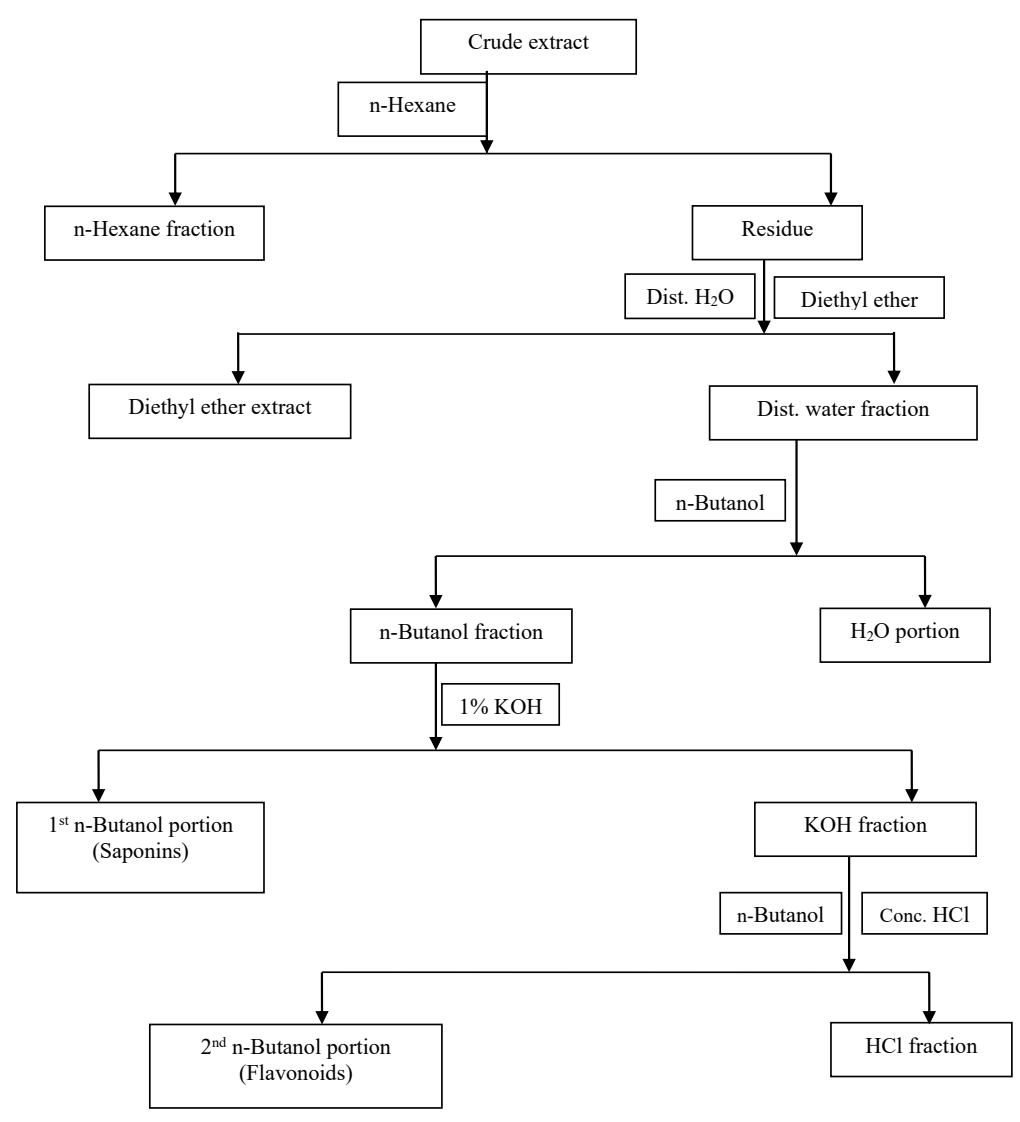

Figure 1. Fractionation of crude saponins and flavonoids (15).

isolates obtained from the Department of Microbiology and Department of Veterinary Medicine, University of Maiduguri.

Screening for antimicrobial activity

The root barks extracts of T. avicennioides and F. polita were subjected to preliminary antimicrobial evaluation on the mentioned strains using the hole-in-plate disc diffusion technique as described by Forbes et al (21) and adopted by Usman et al (22). Wells were bored on the media using $6 \mathrm{~mm}$ cork borer and were filled with $0.2 \mathrm{~mL}$ aliquots of various concentrations of the extracts $(100 \mathrm{mg} /$ $\mathrm{mL}, 50 \mathrm{mg} / \mathrm{mL}$ and $25 \mathrm{mg} / \mathrm{mL}$ equivalent to 20,10 and $5 \mathrm{mg} /$ hole respectively). The agar plates were then kept in an incubator at $37^{\circ} \mathrm{C}$ for 24 hours. After incubation, diameters of inhibition zone for each extract were measured in millimeters using a transparent metre rule. Each extract was tested in triplicates.

\section{Results}

The results of phytochemical contents of the crude extracts of T. avicennioides and F. polita are presented in Table 1 while the antimicrobial effects of the crude saponins and crude flavonoids fraction of the root bark extracts $f$ the two-plant species are shown in Table 2.

The Phytochemical screening of both extracts revealed the presence of flavonoids, terpenoids, phlobatannins and tannins. T. avicennioides contained alkaloids and saponins. None of the extracts showed the presence of anthraquinones (Table 1).

Antimicrobial evaluation

The results of antimicrobial studies showed that the crude saponins appeared to be less active compared to the crude flavonoids at all the dosages against the test microorganisms except against $S$. aureus where the crude saponins portion of $T$. avicceniodes was more effective than crude flavonoids with DIZ values of $34.70 \pm 0.58$ and $30.70 \pm 0.58 \mathrm{~mm}$, respectively at the highest dosage of 20 $\mathrm{mg} /$ hole as shown in Table 2. Moreover, T. avicceniodes was more effective than F. polita.

Table 1. Phytochemical evaluation of the root bark crude extracts of Terminalia avicennioides and Ficus polita

\begin{tabular}{lcc}
\hline Constituents & T. avicennioides & F. polita \\
\hline Alkaloids & + & - \\
Flavonoids & + & + \\
Phlobatannins & + & + \\
Free Anthraquinones & - & - \\
Combined Anthraquinones & - & - \\
Tannins & + & + \\
Terpenoids & + & + \\
Saponins & + & - \\
\hline
\end{tabular}


Table 2. Antimicrobial susceptibility pattern of the root bark extracts of Terminalia avicennioides and Ficus polita against some microorganisms

\begin{tabular}{|c|c|c|c|c|c|c|}
\hline \multirow{4}{*}{ Organisms/Plant species } & \multicolumn{6}{|c|}{ Extract fractions } \\
\hline & \multicolumn{3}{|c|}{ Crude saponins } & \multicolumn{3}{|c|}{ Crude flavonoids } \\
\hline & \multicolumn{3}{|c|}{$\begin{array}{l}\text { Concentrations/diameter of inhibition zone }(\mathrm{mm}) \text { as } \\
\text { Mean } \pm \text { SEM }\end{array}$} & \multicolumn{3}{|c|}{$\begin{array}{l}\text { Concentrations/diameter of inhibition zone }(\mathrm{mm}) \text { as } \\
\qquad \text { Mean } \pm \text { SEM }\end{array}$} \\
\hline & $20 \mathrm{mg} / \mathrm{hole}$ & $10 \mathrm{mg} / \mathrm{hole}$ & $5 \mathrm{mg} /$ hole & $20 \mathrm{mg} / \mathrm{hole}$ & $10 \mathrm{mg} / \mathrm{hole}$ & $5 \mathrm{mg} /$ hole \\
\hline \multicolumn{7}{|l|}{ Staphylococcus aureus } \\
\hline T. avicennioides & $34.70 \pm 0.58$ & $30.70 \pm 0.57$ & $22.30 \pm 0.58$ & $30.70 \pm 0.58$ & $24.30 \pm 0.58$ & $18.70 \pm 0.58$ \\
\hline F. polita & $24.00 \pm 1.15$ & $20.00 \pm 0.00$ & $14.46 \pm 0.58$ & $29.67 \pm 0.58$ & $24.00 \pm 1.00$ & $18.33 \pm 1.15$ \\
\hline \multicolumn{7}{|l|}{ Shigella dysenteriae } \\
\hline T. avicennioides & $19.70 \pm 0.58$ & $15.70 \pm 0.58$ & $11.33 \pm 0.58$ & $24.70 \pm 0.58$ & $21.30 \pm 0.58$ & $14.30 \pm 0.58$ \\
\hline F. polita & $15.00 \pm 0.0$ & $11.67 \pm 0.58$ & $9.67 \pm 0.58$ & $23.67 \pm 0.58$ & $20.00 \pm 0.00$ & $14.67 \pm 0.58$ \\
\hline \multicolumn{7}{|l|}{ Salmonella Typhi } \\
\hline T. avicennioides & $19.70 \pm 0.58$ & $30.70 \pm 0.58$ & $22.30 \pm 0.58$ & $30.70 \pm 0.58$ & $24.30 \pm 0.58$ & $18.00 \pm 0.58$ \\
\hline F. polita & $16.0 \pm 0.00$ & $12.67 \pm 0.58$ & $11.00 \pm 0.00$ & $27.67 \pm 0.58$ & $22.33 \pm 2.80$ & $16.33 \pm 0.58$ \\
\hline \multicolumn{7}{|l|}{ Pseudomonas aeruginosa } \\
\hline T. avicennioides & $18.00 \pm 1.00$ & $13.30 \pm 0.57$ & $11.00 \pm 0.00$ & $34.70 \pm 0.58$ & $28.70 \pm 0.58$ & $20.00 \pm 0.00$ \\
\hline F. polita & $18.00 \pm 0.00$ & $13.67 \pm 0.58$ & $10.33 \pm 0.58$ & $30.67 \pm 0.58$ & $26.33 \pm 0.58$ & $20.67 \pm 0.58$ \\
\hline \multicolumn{7}{|l|}{ Candida albicans } \\
\hline T. avicennioides & $0.00 \pm 0.00$ & $0.00 \pm 0.00$ & $0.00 \pm 0.00$ & $22.30 \pm 0.58$ & $18.30 \pm 0.58$ & $13.00 \pm 0.00$ \\
\hline F. polita & $0.00 \pm 0.00$ & $0.00 \pm 0.00$ & $0.00 \pm 0.00$ & $24.67 \pm 0.58$ & $20.33 \pm 1.20$ & $17.33 \pm 0.58$ \\
\hline
\end{tabular}

Data are mean of triplicate values $(n=3)$.

\section{Discussion}

The dependence on traditional medicine may be due to the perceived activities of medicinal plants. Phytochemical screening conducted on the root extracts (Table 1) revealed the presence of compounds which are known to exhibit therapeutic activities (23). These compounds are flavonoids, saponins, sterols and triterpenes. The presence of secondary metabolites in T. avicennioides is an indication that the root extract is of pharmacological importance and also justified their potential use as a drug by local people. The plants contained terpenes which are believed to be useful in the prevention and therapy of several diseases. Terpenoids are also known to possess antimicrobial, antifungal, antiparasitic, antiviral, anti-allergenic, antispasmodic, antihyperglycemic, antiinflammatory and immunomodulatory properties (24). The presence of this compound probably justifies the use of the selected plants for the treatment of microbial infections. Flavonoids are phenolic substances known to be synthesized by plants in response to microbial infections and have been reported to exhibit antimicrobial properties against wide variety of microorganisms. The activity of flavonoids is probably due to their ability to complex with extracellular and soluble proteins and also to complex with bacterial cell walls (25). In addition, sterols present in most of our plant samples, have been reported to have antibacterial properties (26) and are very important compounds especially due to their relationship with compounds like sex hormones (27). The absence of alkaloids and saponins in Ficus polita Vahl in the present work is in contrast with the opinion of Gills (28) and Kasolo et al (29) who noted that saponins and alkaloids were two of the active constituents. Alkaloids are known to have antimicrobial properties possibly due to their ability to intercalate with DNA of the microorganisms. Also, the presence of saponins in T. avicinnioides is in agreement with previous findings (30).

In the present study, the results of antimicrobial property of the 2 root bark extracts (Table 2) against tested microorganisms varied on species tested and. However, both root extracts showed inhibition zones against S. typhi, S. dysenteriae, P. aeruginosa and S. aureus, respectively. Nevertheless, resistances against $C$. albicans exhibited by both extracts do not indicate the absence of bioactive constituents, nor that the roots extracts were completely inactive; but rather resistance at the working concentration. It was noticed that $T$. avicennioides which showed the highest antibacterial activity could probably be due to the fact that the rate of the active constituents in the root extract is higher than that obtained in F. polita. Preliminary phytochemical screening of T. avicennioides roots showed that they possessed flavonoids, terpenes and saponins. Phytoconstituents such as flavonoids, triterpenes and saponins have been reported to inhibit bacterial growth and to be protective to plants against microbial infestations (30). The presence of saponins in this plant must have elicited direct antibacterial activity and suppression of bacterial virulence resulting to the 
antimicrobial activity observed in this study (28).

\section{Conclusion}

The results of the present study offer a scientific basis for the use of the studied extracts in the treatment of infectious diseases. These plants species can be regarded as promising resources for drug development. However, further investigations are necessary in order to draw solid conclusions.

\section{Acknowledgements}

The authors wish to acknowledge the technical assistance rendered by Mr. Fine Akawo of Chemistry Department and Alhaji Isa Adamu Gulani of Department of Veterinary Medicine, University of Maiduguri, Nigeria.

\section{Authors' contributions}

All authors contributed to the study. AUK and OOI acquired data. AMF and HU prepared the draft. HU and IAA revised the manuscript critically for important intellectual content and HU submitted it. All read and confirmed the article ready for publication.

\section{Conflict of interests}

The authors declared no competing interests exist.

\section{Ethical considerations}

Ethical issues (including plagiarism, misconduct, data fabrication, falsification, double publication or submission, redundancy) have been completely observed by the authors.

\section{Funding/Support}

This research was financially self-funded and supported by the authors.

\section{References}

1. Jamshidi-Kia F, Lorigooini Z, Amini-Khoei H. Medicinal plants: Past history and future perspective. J Herbmed Pharmacol. 2018;7(1):1-7. doi: 10.15171/jhp.2018.01.

2. Shimada T. Salivary proteins as a defense against dietary tannins. J Chem Ecol. 2006;32(6):1149-63. doi: 10.1007/ s10886-006-9077-0.

3. Sofowora A. Medicinal Plants and Traditional Medicine in Africa. 3rd ed. Ibadan, Nigeria: Spectrum Books Limited; 2008.

4. Bauer PDR. Quality Criteria and Standardization of Phytopharmaceuticals: Can Acceptable Drug Standards be Achieved? Drug Inf J. 1998;32(1):101-10. doi: 10.1177/009286159803200114.

5. Masoko P, Picard J, Eloff JN. Antifungal activities of six South African Terminalia species (Combretaceae). J Ethnopharmacol. 2005;99(2):301-8. doi: 10.1016/j. jep.2005.01.061.

6. Cragg GM, Newman DJ. Biodiversity: A continuing source of novel drug leads. Pure Appl Chem. 2005;77(1):7-24. doi: 10.1351/pac200577010007.
7. Abdullahi AL, Agho MO, Amos S, Gamaniel KS, Wambebe C. Antidiarrhoeal activity of the aqueous extract of Terminalia avicennoides roots. Phytother Res. 2001;15(5):431-4.

8. Akinsinde KA, Olukoya DK. Vibriocidal activities of some local herbs. J Diarrhoeal Dis Res. 1995;13(2):127-9.

9. Akinyemi KA. Antibacterial screening of five Nigerian Medicinal Plants against S. typhi and S. paratyphi. Journal Nigerian Infection Control Association. 2000;3(1):30-3.

10. Akinyemi KO, Oladapo O, Okwara CE, Ibe CC, Fasure KA. Screening of crude extracts of six medicinal plants used in South-West Nigerian unorthodox medicine for antimethicillin resistant Staphylococcus aureus activity. BMC Complement Altern Med. 2005;5(1):6. doi: 10.1186/14726882-5-6.

11. Mann A, Banso A, Clifford LC. An antifungal property of crude plant extracts from Anogeissus leiocarpus and Terminalia avicennioides. Tanzan J Health Res. 2008;10(1):34-8.

12. Kuete V, Kamga J, Sandjo LP, Ngameni B, Poumale HM, Ambassa P, et al. Antimicrobial activities of the methanol extract, fractions and compounds from Ficus polita Vahl. (Moraceae). BMC Complement Altern Med. 2011;11:6. doi: 10.1186/1472-6882-11-6.

13. Etkin NL, Ross PJ. Food as medicine and medicine as food. An adaptive framework for the interpretation of plant utilization among the Hausa of Northern Nigeria. Soc Sci Med. 1982;16(17):1559-73.

14. Kamga J, Sandjo LP, Poumale HM, Ngameni B, Shiono Y, Yemloul M, et al. Politamide, a new constituent from the stem bark of Ficus polita Vahl (Moraceae). Arkivoc. 2010;2:323-9.

15. Won SW, Shin KH, Kang SS. Chemistry and pharmacology of flavone-c-glycoside from Ziziphus seeds. Kor J Pharmacog. 1980;11:141-8.

16. Silva LG, Lee IS, Kinghorn DA. Special problem with the extraction of plants. In: Natural Products Isolation. New Jersey, USA: Humana Press Inc; 1998:343-364.

17. Evans WC. Trease and Evans Pharmacognosy. 15th ed. Elsevier India; 2002;3-554.

18. Vishnoi NR. Advanced Practical Chemistry. Ghaziabad India: Yikas Publication House PVT Ltd; 1979:447-9.

19. Brain KR, Turner TD. The practical evaluation of phytopharmaceuticals. 1st ed. Bristol: WrightScientechnica; 1975.

20. Markham KR. Techniques of flavonoids identification. London: Academic press; 1982:38-9.

21. Forbes BA, Sahm DF, Trevino AS. Methods for testing antimicrobial effectiveness. In: Baron EJ, Peterson S, Finegold SM, eds.Bailey and Scott's Diagnostic Microbiology. St. Louis; Mosby Co; 1990:171-194.

22. Usman H, Abdulrahman F, Usman A. Qualitative phytochemical screening and in vitro antimicrobial effects of methanol stem bark extract of Ficus thonningii (Moraceae). Afr J Tradit Complement Altern Med. 2009;6(3):289-95.

23. Sofowora A. Medicinal plants and traditional medicine in Africa. Ibadan, Nigeria: Spectrum Books Ltd; 1993;191289.

24. Wagner KH, Elmadfa I. Biological relevance of terpenoids. 
Overview focusing on mono-, di- and tetraterpenes. Ann Nutr Metab. 2003;47(3-4):95-106. doi: 10.1159/000070030.

25. Cowan MM. Plant products as antimicrobial agents. Clin Microbiol Rev. 1999;12(4):564-82.

26. Epand RF, Savage PB, Epand RM. Bacterial lipid composition and the antimicrobial efficacy of cationic steroid compounds (Ceragenins). Biochim Biophys Acta. 2007;1768(10):2500-9. doi: 10.1016/j.bbamem.2007.05.023.

27. Okwu DE. Evaluation of chemical composition of medicinal plants belonging to Euphorbiaceae. Pak Vet J. 2001;14:160-2.
28. Gills LS. Ethnomedical uses of plants in Nigeria. Nigeria: University of Benin Press; 1992:276.

29. Kasolo JN, Bimenya GS, Ojok L, Ochieng J, OgwalOkeng JW. Phytochemicals and uses of Moringa oleifera leaves in Ugandan rural communities. J Med Plants Res. 2010;4(9):753-7. doi: 10.5897/JMPR10.492.

30. Yusha'u M, Taura DW, Bello B, Abdullahi N. Screening of Annona squamosa extracts for antibacterial activity against some respiratory tract isolates. Int Res J Pharm Pharmacol. 2011;1(9):237-41. 